\title{
MEDIATING SOCIAL TOURISM EXPERIENCES THROUGH A MOBILE APPLICATION
}

\author{
Luís C. S. Barradas ${ }^{\mathrm{a}, \mathrm{b}}$, João Nascimento ${ }^{\mathrm{a}}$, Sandra Oliveira ${ }^{\mathrm{a}, \mathrm{c}}$, Susana Leal ${ }^{\mathrm{a}, \mathrm{d}}$, Carla Vivas ${ }^{\mathrm{a}}$ \\ and André Alves ${ }^{\mathrm{a}}$ \\ ${ }^{a}$ Instituto Politécnico de Santarém, Complexo Andaluz, Apartado 295, 2001-904 Santarém, Portugal \\ ${ }^{b}$ Digital Services, Applications and Content Research \& Development Unit, Av. do Empresário, 6000-767 Castelo \\ Branco, Portugal \\ ${ }^{c}$ Centre for Health Studies and Research, University of Coimbra, Avenida Dias da Silva 165, 3004-512 Coimbra, \\ Portugal \\ ${ }^{d}$ Life Quality Research Centre, Complexo Andaluz, Apartado 279, 2001-904 Santarém, Portugal
}

\begin{abstract}
Nowadays, mobile devices are an essential mean for accessing information. Over time, industries and businesses have been exploring this phenomenon extensively to gain market share and competitive advantage. This is especially true in the tourism industry where mobile applications are crucial in the modern e-Tourism model. This paper presents a mobile application that aims to support the management of social tourism initiatives and the mediation of tourist experiences, within the context of a senior exchange programme in social economy organisations. The mobile application design was guided by the Dynamic Systems Development Method framework and takes a set of requirements and specific needs of each stakeholder into account. The developed software artefact is a mobile hybrid application that provides an almost native user experience, fulfilling its design objectives and purpose.
\end{abstract}

\section{KEYWORDS}

Social Tourism, Mobile Applications, Tourism Experience Mediation, Elderly

\section{INTRODUCTION}

The desire to travel to meet and establish relationships with other people and civilisations has been a constant throughout the history of mankind. Since time immemorial, travel has been important not simply to ensure subsistence (Cunha, 2013) but for a host of other reasons, be they religious, commercial, political, territorial expansion, or even mere curiosity. Although tourism is typically seen as "travelling for fun", this definition has recently been expanded to include any displacement outside the normal area of work or residence. Nowadays, tourism is a gigantic international industry in constant change that embraces various other industries such as transportation, hotels, restaurants, handicrafts, etc. Information and communication technologies quickly assumed a significant role in this process, supporting not only core activities in the tourism industry value chain (Cunha, 2013, Kazandzhieva and Santana, 2019, Osei et al., 2020) but also innovative business models (Presenza et al., 2020) and the mediation of tourism experiences (Hyun et al., 2009) where mobile applications emerge as a key element (Figueiredo, 2014, Raposo et al., 2012).

Opportunities to travel and experience touristic offers are not transversal to all sectors of modern society for several reasons, even in the so-called "developed countries". European Union (EU) countries are facing an ageing process due to the increase in overall life expectancy and Portugal is no exception to this trend. It is estimated that the old-age dependency ratio of the EU population in 2070 will be $51.2 \%$ with 266.24 million people over the age of 65 (European Union, 2018). As in the health industry, a process of adaptation is underway in the tourism industry to meet this new demand. The rise in active ageing practices alongside the growing importance of quality of life for the elderly has led to a greater willingness to participate in this sort of touristic offer. Moreover, many seniors lack financial or economic resources and face increased social difficulties as the population grows (Oliveira et al., 2019); indeed, a large proportion of Portuguese seniors cannot afford the touristic packages targeting this group. This is particularly true for the elderly population in 
institutions who often face economic and social difficulties and, many of those from inland regions have never even seen the sea or travelled outside their municipality. Touristic packages targeting this group need to be specially adapted to their profile. To address this problem, the VOLTO JÁ Project (Oliveira et al., 2019) proposes a social tourism business model supported by information and communication technologies.

This paper presents the VOLTO JÁ Mobile Application (VJAPP) which aims to support and mediate the three critical stages of the tourist experience (Figueiredo, 2014) within the scope of social tourism addressed by the VOLTO JÁ Project.

The paper is organised as follows: Section 2 presents a survey on mobile tourism applications and the challenges related to their use by the elderly. Section 3 presents the mobile application development methodology, main functionalities, architecture building blocks, supporting technology, and how the application mediates the users' tourism experience. This is followed by the discussion in Section 4. Finally, Section 5 presents the conclusions and limitations, and proposes future research avenues.

\section{MOBILE TOURISM APPLICATIONS AND ELDERLY USERS}

Modern mobile e-Tourism has allowed tourists to deal with almost every aspect of travel a using a mobile application: (1) choosing the destination; (2) finding attractions and points of interest; (3) booking transportation, accommodation, and activities; (4) receiving on-site support; and (5) sharing their experience. Some aspects of travel planning were formerly reserved to travel agencies. Today, mobile technologies can assist tourists in every stage of their travel and many mobile applications are available for this purpose. Kennedy-Eden and Gretzel (2012), Wang and Xiang (2012), Gavalas et al. (2014), Borràs et al. (2014), and Wörndl and Herzog (2020) conducted surveys aiming to classify these mobile tourism applications. According to Wörndl and Herzog (2020) taxonomy, they can be classified into four major groups, as shown in Table 1.

Table 1. Classification of mobile applications for tourism. Adapted from Wörndl and Herzog (2020)

\begin{tabular}{|c|c|c|}
\hline Application category & Purpose & Examples \\
\hline Information and Sharing & $\begin{array}{l}\text { Destinations } \\
\text { Points of Interest } \\
\text { Activities }\end{array}$ & $\begin{array}{l}\text { TripAdvisor } \\
\text { FourSquare } \\
\text { TripAdvisor }\end{array}$ \\
\hline Booking & $\begin{array}{l}\text { Accommodation } \\
\text { Transportation } \\
\text { Activities }\end{array}$ & $\begin{array}{l}\text { Booking.com; Trivago; Airbnb } \\
\text { TAP Air Portugal; eDreams; Booking.com } \\
\text { TripAdvisor }\end{array}$ \\
\hline On-trip Services & $\begin{array}{l}\text { Help \& Support } \\
\text { Navigation \& Transport } \\
\text { Safety }\end{array}$ & $\begin{array}{l}\text { National Park Passport Book; Louvre Travel Guide } \\
\text { Lisboa Viagem; Uber } \\
\text { Can I Go? }\end{array}$ \\
\hline Sharing \& Interaction & $\begin{array}{l}\text { Social } \\
\text { Virtual Tourism } \\
\text { Others }\end{array}$ & $\begin{array}{l}\text { Instagram; FourSquare Swarm } \\
\text { VR Travel; Iran Tour; Google Arts \& Culture } \\
\text { Google Translator }\end{array}$ \\
\hline
\end{tabular}

Despite this segmentation, many of the applications often combine functionalities from several application categories. For example, TripAdvisor combines features from Information and Sharing and Booking categories. Although some other applications, such as Pokemon Go!, cannot be included in any of the above categories, they are used by both travellers and the general population.

Mobile applications can provide a pleasant user experience to travellers by assisting them with personalised services and helping tourism service providers to understand their customers and adapt their offers accordingly. However, the intrinsic characteristics of mobile devices (e.g., screen size) present some interaction challenges to users, notably the impaired and elderly (Ribeiro et al., 2018a). The acceptance and use of mobile devices and applications by the elderly remains an active field of study. There are several mobile applications on the market for the elderly but they seldom meet the specific needs of this target group due to their physical and cognitive impairments (Klimova, 2018).

The literature reveals some remarkable projects addressing the use of mobile applications for the elderly in tourism. For example, $\mathrm{E}^{2}$ (Khadraoui et al., 2014) comprises a web system and a mobile application that aims to allow the elderly to plan their trips in line with their constraints and preferences; Trip 4 All (Signoretti et al., 2015) is a mobile application that works as a gamified virtual assistant to the elderly during a walking tourist visits; Sweet Mobility (Borrelli et al., 2015) is a smartphone-based system to promote walking for the 
elderly and empower tourism; and finally, iTourism Travel Buddy (Ismail et al., 2016) is a mobile tourism application that supports tourism information with assistive travel features to help tourists by using technology that is closest to them.

The elderly population is of growing importance in e-Tourism and the supporting technologies must be adapted to their specific needs.

\section{VOLTO JÁ MOBILE APPLICATION}

The VOLTO JÁ Mobile Application is a component of the VOLTO JÁ Information System (VJIS). The design of the VJIS was guided by the Dynamic Systems Development Method framework (Anwer et al., 2017, DSDMC, 2014). This paper encompasses only the Business study (partially), the Functional Model Iteration, and the Implementation Iteration.

\subsection{The VOLTO JÁ Business Model}

The VOLTO JÁ Project focuses on Social Tourism for low-income groups, particularly institutionalised seniors in homes for senior citizens or nursing homes who would not otherwise go on holiday. Special emphasis is given to what motivates the elderly populations to have new cultural experiences and the impact this may have on their active ageing and quality of life. The project is essentially a social senior exchange programme in Social Economy Entities (SEE) that promote cultural, touristic, and artistic experiences. It encompasses a set of activities that directly impact the mobility and active ageing of seniors.

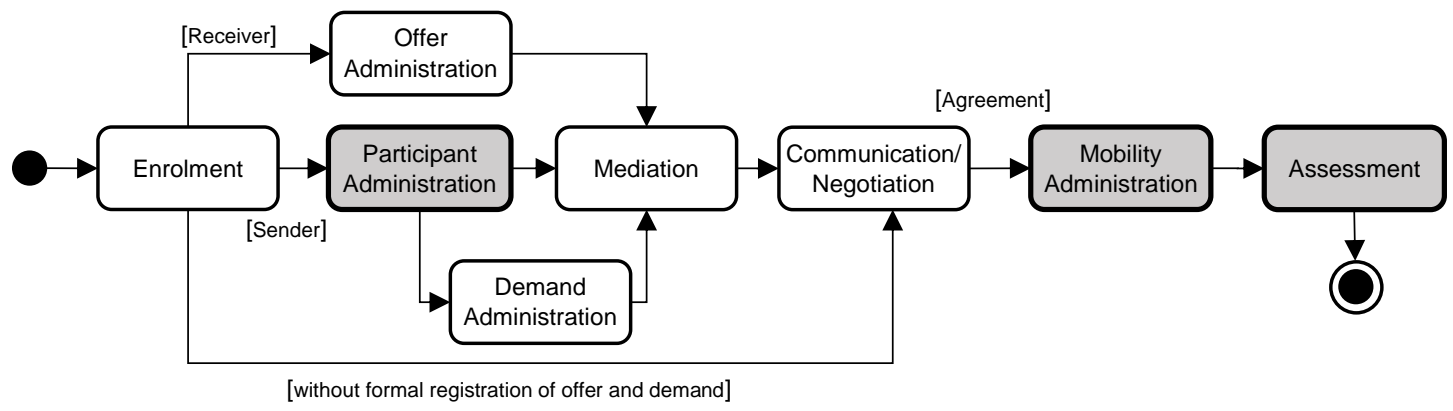

Figure 1. VJBM business processes co-supported by VJAPP. Adapted from (Author Citation)

The VOLTO JÁ Business Model (VJBM) lies on eight core business processes (see Figure 1) and considers four key players: (1) Social Economy Entities that provide housing and care services to the elderly; (2) the Social Economy Entities Directors (SEED), who are the main representatives of SEEs; (3) SEE users (also referred to as participants), who are the institutionalised elderly in SEE; and (4) the SEE companions (also referred to as teammates) who are the SEE people who accompany the participants in the mobilities (senior interchanges). The VJBM is operationalised by VJIS comprising a web platform (Barradas et al., 2019) and a mobile application. While the web platform, far more complex, aims to support the whole set of business processes of the VJBM, the mobile application seeks to co-support only three core business processes. Figure 1 highlights the subset of VJBM core business processes (in grey) co-supported by the mobile application from the SEE perspective.

\subsection{Requirements and Functionalities}

As noted above, the mobile application is a component of VJIS. The list of VJIS requirements was produced based on the VJBM business processes presented in Figure 1. The consolidated list of requirements comprised sixty-one items, which was shortened to forty-five (27 mandatories; 9 important; 8 suggested; 1 excluded) after refinement through the MoSCoW technique (DSDMC, 2014). All the non-excluded requirements became part of the list of VJIS functionalities, fifteen of which were relative to the mobile application. Figure 2 presents 
the top-level UML use case diagram of the mobile application. In addition to showing technical requirements (Login and Abandon session) and a generic requirement (View public contents), it also represents the supported VJBM core business processes as packages.

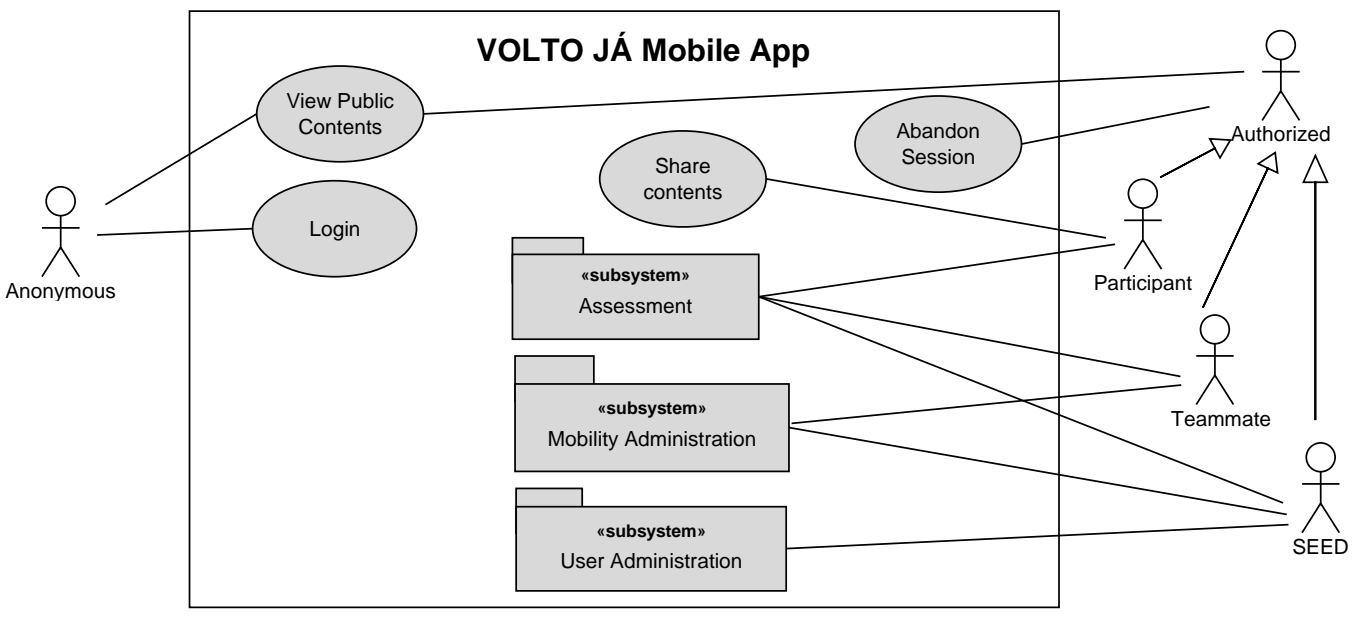

Figure 2. VJAPP top-level UML use case

Public content refers to any that can be viewed in an unrestricted environment; this includes information about the project, the offers or demands as a result of a search process, the elderly mobilities that have already taken place, and the content shared (posts tagged as public, containing comments and photos) by the participants in the scope of those mobilities, reflecting their lived tourism experience. The Teammates and the SEEDs assess participants' posts. Finished mobilities are also assessed quantitatively by the Participants and SEEDs.

SEEDs can administrate both the users of the system (only participants and Teammates) and mobilities; they are able to: (1) open mobilities; (2) view details about the mobilities (e.g., listing details of participants involved and teammates, tourism programme of mobilities, transportation and feeding aspects of mobilities); and (3) close the running mobilities. Teammates can also view details about the participants and the mobilities in which they are involved.

\subsection{Application Architecture and Development Technology}

The mobile application builds on a modular three-tier layered architecture (see Figure 3). The presentation layer, responsible for the user interface (UI), comprises four functional modules. The "anonymous" module provides access to general functionalities for which no authentication is required for access, such as searching for offers and demands, accessing contents of mobilities carried out (with public access), generic information about the mobility programme, partner entities, and their geographic location. The SEED module is aimed at SEEDs and provides access to features related to the administration of participants and Teammates, administration of mobilities (consulting data, opening mobilities and closing mobilities), validation of published content, and mobility evaluation by participants. The Companion module is aimed at Teammates and provides functionalities for consulting data on mobilities in which they participate or have participated and validating content published by participants. The Participants module is for participants and provides functionalities for consulting data on mobilities in which they participated, sharing content about these mobilities, and assessing mobilities based on their experience.

The Application layer comprises models and components and is responsible for the application logic and task orchestration in line with business rules.

Finally, the Service layer offers an abstraction layer for accessing persistent data, integrating the mobile application with the web platform through the consumption of REST services. It provides a set of services that deal with functional, security/authentication, or utility concerns. 


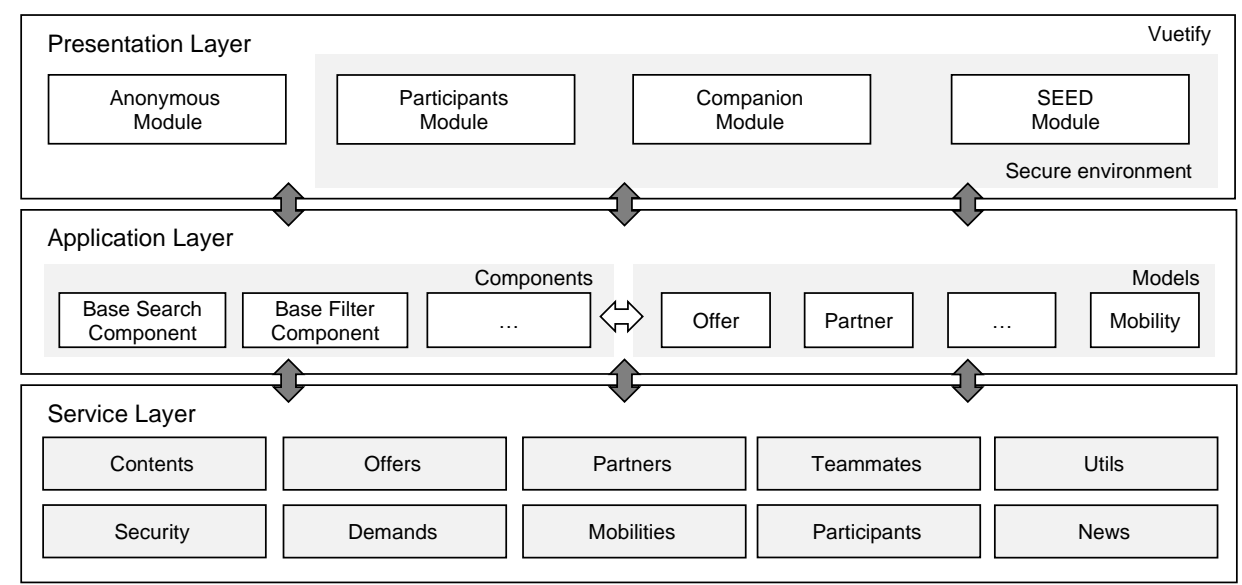

Figure 3. VJAPP architecture

In the current scenario of mobile application development, three types of applications can be considered: (1) native applications; (2) cross-platform applications; and (3) hybrid applications (Majchrzak et al., 2018). In this research work, the development technology was selected using three main criteria: (1) independence of the platform/execution environment; (2) time to market; and (3) familiarity with the development technologies. To meet these criteria, it was decided to construct a hybrid application, allowing the development of a mobile application based on web technologies (familiarity) running on the WebView component present in the Android and iOS platforms. Although this approach provides lower performance when compared to other alternatives, this criterion was considered as not relevant for the technology selection decision-making process.

The Vue.js JavaScript framework was the selected technology for implementation. This framework allowed the application to be developed in a single-page model using the Vue Router component (Rojas, 2020). The UI was developed using Vuetify, a complete UI framework built on top of Vue.js. This framework provides semantic UI components based on the Material Design specification, which permits a UI design that offers engaging, native-like mobile user experiences. The development of Vue.js applications follows the Model-View-ViewModel pattern; this allows reactive behaviours, i.e., any changes made in the models, are immediately reflected in the UI and vice versa.

Concerning security aspects, the communication between the web platform and the mobile application involves a 32-byte token exchange (bearer authentication). Even the consumption of unrestricted content requires the use of tokens to avoid denial of service attacks.

Ionic Capacitor (Huber et al., 2020) was selected as cross-platform native runtime, which allows transparent access to the device resources (such as camera, location services, network status, file system, etc.) through plugins; and to export/deploy them to Android or iOS platforms.

\subsection{Mediating Participants' Tourism Experience}

According to Milano et al. (2011), on a technology-mediated tourism experience, three phases are influential in the travel experience formation process: (1) pre-experience, built on other people's travel stories before travelling; (2) experience during travel or stay, now shared increasingly in real-time through mobile applications; and (3) post-experience, which disseminates comments, evaluations, and emotions. Figure 4 depicts the participants' mobility experience mediation through the VOLTO JÁ Mobile Application. The pre-experience phase begins when the participants list mobilities carried out and see the contents (comments, photos) shared by people about their experience in that mobility (see Figure 5a, b); or search for available offers/demands in a destination of their preference. 


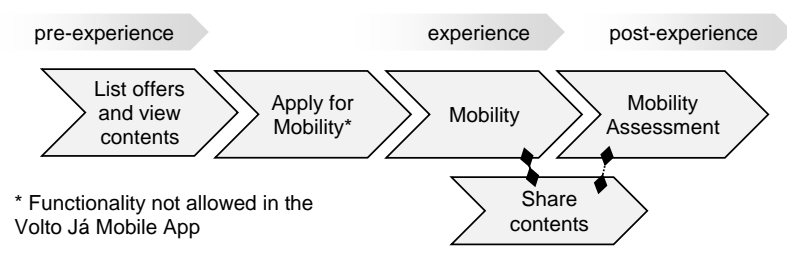

Figure 4. Participants' mobility experience activities supported by VJAPP

After applying for mobility, and once negotiations between the partner institutions are concluded, the experience phase starts with the arrival of the participants at the host institution. During the mobility, participants can feed the system with comments and photos about their own mobility tourism experience (see Figure 5c). Participants can define the visibility level of their published content. Only the content defined as "public" can be accessed in unrestricted environments. Participants can set a shared content as "private", "visible to the group", "visible to the Institution", "visible to the mobility", "visible to authorised users", or "public". A Teammate or a SEED is responsible for reviewing any shared content, and only approved content can be made available.

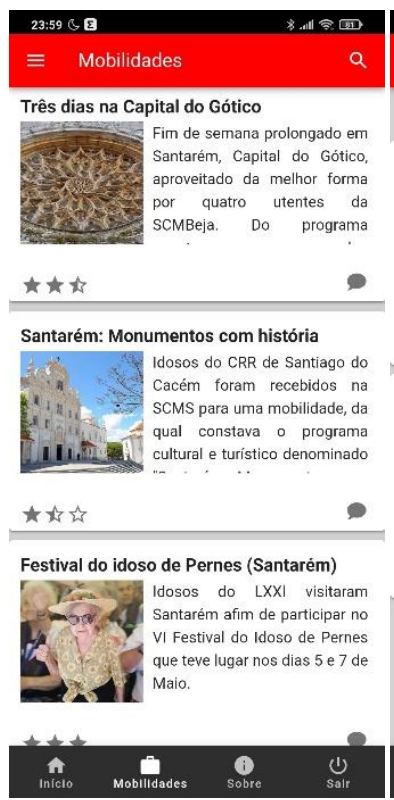

a)

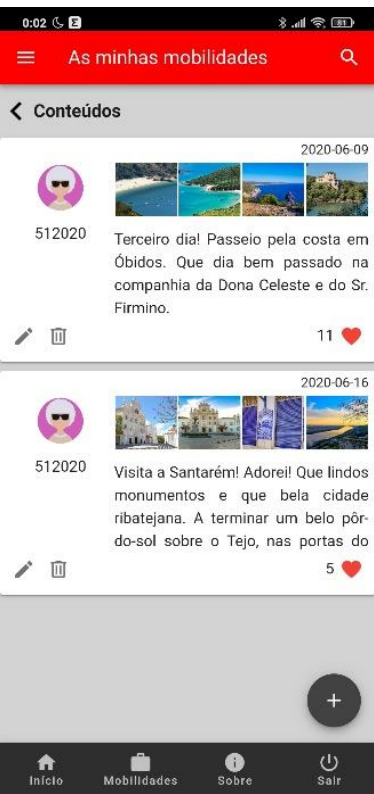

b)

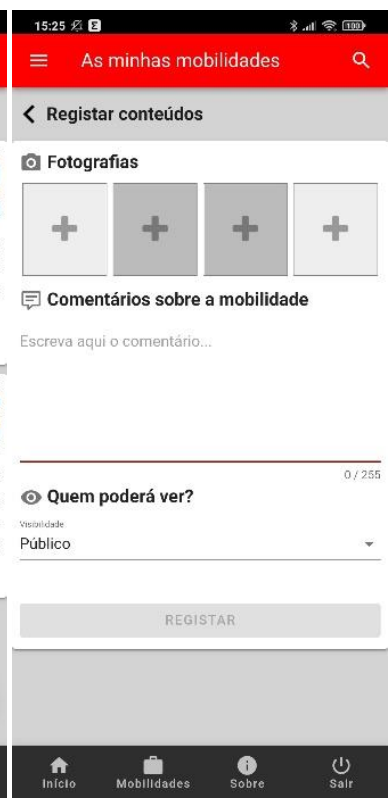

c)

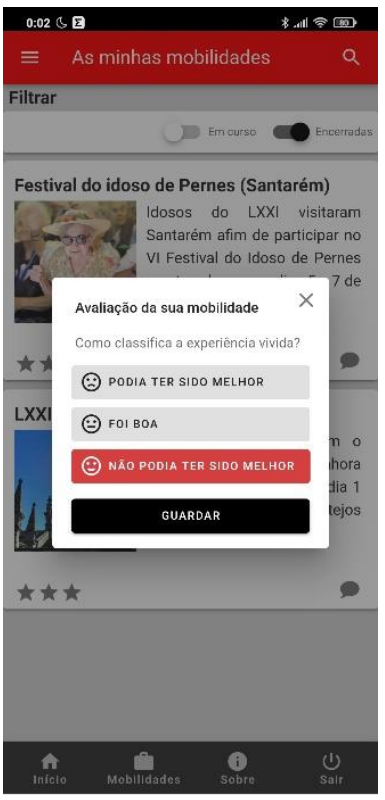

d)

Figure 5. Participants' mobile views related to mobility experience mediation

The post-experience phase begins when the mobility ends (participants arrive at their home institution). At this stage, participants can review and rate their experience (see Figure 5d). Participants can continue to share and publish content while the mobility status remains "open".

\section{DISCUSSION}

The mobile application developed has two fundamental objectives: to facilitate the administration of mobility to SEED and companions through their ubiquity; and to mediate the participants' tourist experience. Despite its simplicity, we believe the application fulfils the purpose for which it was designed. This simplicity is due to the target user population, notably participants, whose physical and cognitive conditions require special requirements in the application design (Klimova, 2018). Within the scope of e-Tourism, Ribeiro et al. (2018a) and Ribeiro et al. (2018b) have already proposed a Framework for accessible tourism mobile application development, although focused on people with disabilities. 
The list of requirements and features initially planned for the application included a wider range of features. However, following recommendations made by the social economy entity partners during focus groups with stakeholders, some functionalities were removed as a result of the very specific characteristics of the elderly in institutions.

\section{CONCLUSION}

From a macro perspective, this work aims to establish a link between senior tourism and a business model for the social economy to promote active ageing and social value creation. To that end, an information system was designed and developed to operationalise the business model and support the underlying processes. While the web platform strives to provide support for the heavy work of operationalising the entire business model, the mobile application presented here aims to mediate the tourism experiences of participants during their mobilities and provides SEED and Teammates with a pocket tool to manage the mobilities in which they are involved.

Mobile applications are now part of our way of life and dozens of mobile applications with varied objectives are used throughout the tourism industry value chain, some of which have similar objectives to the Volta Já mobile app. However, the originality of this work lies in the nature and particularities of the target group.

Due to the world COVID-19 pandemic, the application has only been tested in a controlled environment because it could not be used in a real scenario. However, this situation will be rectified as soon as the necessary security health conditions are restored to assess its utility. Unit, integration, and functional tests were performed to assess the quality and efficiency of the application.

Given the national scope of this research project, the business specificities and the implemented business rules are only applicable to the Portuguese context. In the future, we aim to internationalize the project by extending the concept to other countries and realities and expand the application by adding new utility services (e.g., weather forecast) and context-aware functionalities.

\section{ACKNOWLEDGEMENT}

The authors wish to thank the Fundação para a Ciência e a Tecnologia (FCT), which is the financing support entity of the project "VOLTO JÁ: PROGRAMA DE INTERCÂMBIO SENIOR" Ref: ALT20-03-0145-FEDER-024111. The authors are also grateful to all the Social Economy Entities that have been active collaborators in the project.

\section{REFERENCES}

Anwer, F., Aftab, S., Waheed, U. \& Muhammad, S. S. (2017). Agile Software Development Models Tdd, Fdd, Dsdm, and Crystal Methods: A Survey. International journal of multidisciplinary sciences and engineering, Vol: 8, pp:1-10.

Barradas, L. C., Nascimento, J., Martins, L., et al. (2019). Developing an Information System for Social Value Creation. Procedia Computer Science, Vol: 164, pp:547-552.

Borràs, J., Moreno, A. \& Valls, A. (2014). Intelligent Tourism Recommender Systems: A Survey. Expert Systems with Applications, Vol: 41, pp:7370-7389.

Borrelli, G., Pistoia, M., Fruttarol, B. \& Paolo, C. (2015). A System to Promote Walking for the Elderly and Empower Tourism: The Sweet Mobility Project. In: Andò, B., Siciliano, P., Marletta, V. \& Monteriù, A. (eds.) Ambient Assisted Living: Italian Forum 2014. Cham: Springer International Publishing.

Cunha, L. (2013). Economia E Política Do Turismo, Lisboa, Lidel.

DSDMC (2014). The Dsdm Agile Project Framework Handbook, Ashford, Kent, UK, DSDM Consortium.

European Union (2018). The 2018 Ageing Report - Economic \& Budgetary Projections for the 28 Eu Member States (2016-2070). In: Union, E. (ed.) European Economy. online: http://data.europa.eu/doi/10.2765/615631.

Figueiredo, C. (2014). A Complexidade Da Experiência Turística Mediatizada E Tecnologicamente Mediada: Uma Reflexão. In: Martins, M. d. L. \& Oliveira, M. (eds.) Comunicação Ibero-Americana: Os Desafios Da Internacionalização. 
Gavalas, D., Konstantopoulos, C., Mastakas, K. \& Pantziou, G. (2014). Mobile Recommender Systems in Tourism. Journal of network and computer applications, Vol: 39, pp:319-333.

Huber, S., Demetz, L. \& Felderer, M. (2020). Analysing the Performance of Mobile Cross-Platform Development Approaches Using Ui Interaction Scenarios. In International Conference on Software Technologies. Cham: Springer International Publishing.

Hyun, M. Y., Lee, S. \& Hu, C. (2009). Mobile-Mediated Virtual Experience in Tourism: Concept, Typology and Applications. Journal of Vacation Marketing, Vol: 15, pp:149-164.

Ismail, A., Kadir, S. A. S. A., Aziz, A., et al. (2016). Itourism Travel Buddy Mobile Application. In: 2016 10th International Conference on Next Generation Mobile Applications, Security and Technologies (NGMAST), 2016. IEEE, 82-87.

Kazandzhieva, V. \& Santana, H. (2019). E-Tourism: Definition, Development and Conceptual Framework. Turizam: međunarodni znanstveno-stručni časopis, Vol: 67, pp:332-350.

Kennedy-Eden, H. \& Gretzel, U. (2012). A Taxonomy of Mobile Applications in Tourism. e-Rev Tour Res (eRTR), Vol: 10, pp:47-50.

Khadraoui, D., Ayed, H. \& Nicolas, D. (2014). Sustainable E2 Mobility Services for Elderly People - Platform System Architecture. 2014 Science and Information Conference. London: IEEE.

Klimova, B. (2018). Acceptance and Use of Mobile Devices and Apps by Elderly People. In: Al-Sharhan, S. A., Simintiras, A. C., Dwivedi, Y. K., Janssen, M., Mäntymäki, M., Tahat, L., Moughrabi, I., Ali, T. M. \& Rana, N. P., eds. Challenges and Opportunities in the Digital Era, 2018 Kuwait City. Springer International Publishing, 30-36.

Majchrzak, T. A., Biørn-Hansen, A. \& Grønli, T.-M. (2018). Progressive Web Apps: The Definite Approach to Cross-Platform Development? Hawaii International Conference on System Sciences. Hawaii.

Milano, R., Baggio, R. \& Piattelli, R. (2011). The Effects of Online Social Media on Tourism Websites. ENTER - International Conference on Information Technology and Travel \& Tourism. Innsbruck.

Oliveira, S., Leal, S., Vivas, C., et al. (2019). A Social Business Model for Active Ageing: The Case of Volto Já Project. I Luso-Brazilian Meeting of Social Education (AGEINGCONGRESS2019). Coimbra, Portugal: Thomson Reuters.

Osei, B. A., Ragavan, N. A., Kandappan, B. \& Mensah, H. K. (2020). "Hospitality Revolution 4.0": A Literature Review on a Unified Typology of Ir 4.0 Technologies for the Tourism and Hospitality Industry in the Era of Covid-19. Asia-Pacific Journal of Innovation in Hospitality and Tourism (APJIHT), Vol: 9, pp:25.

Presenza, A., Panniello, U. \& Messeni Petruzzelli, A. (2020). Tourism Multi-Sided Platforms and the Social Innovation Trajectory: The Case of Airbnb. Creativity and Innovation Management, Vol: n/a, pp:1-16.

Raposo, R., Pereira, P. M. B., Figueiredo, C. \& Santos, H. (2012). A Abordagem Do E-Tourism Como Um Ecossistema De Inter-Influências Composto Por Rizomas De Redes Pessoais. Revista Turismo \& Desenvolvimento, Vol: 1, pp:351-361.

Ribeiro, F. R., Silva, A., Barbosa, F., et al. (2018a). Mobile Applications for Accessible Tourism: Overview, Challenges and a Proposed Platform. Information Technology \& Tourism, Vol: 19, pp:29-59.

Ribeiro, F. R., Silva, A., Metrôlho, J. C., et al. (2018b). A New Framework for Accessible Tourism Mobile Application Development. International Journal of Mobile Computing and Multimedia Communications (IJMCMC), Vol: 9, pp:31-46.

Rojas, C. (2020). Making Your First Progressive Web App. Building Progressive Web Applications with Vue.Js: Reliable, Fast, and Engaging Apps with Vue.Js. Berkeley, CA: Apress.

Signoretti, A., Martins, A. I., Almeida, N., et al. (2015). Trip 4 All: A Gamified App to Provide a New Way to Elderly People to Travel. Procedia Computer Science, Vol: 67, pp:301-311.

Wang, D. \& Xiang, Z. (2012). The New Landscape of Travel: A Comprehensive Analysis of Smartphone Apps. Vienna: Springer Vienna.

Wörndl, W. \& Herzog, D. (2020). Mobile Applications for E-Tourism. In: Xiang, Z., Fuchs, M., Gretzel, U. \& Höpken, W. (eds.) Handbook of E-Tourism. Springer, Cham. 